University of Nebraska - Lincoln

DigitalCommons@University of Nebraska - Lincoln

\title{
BEDSIDE ESTIMATION OF PATIENT HEIGHT FOR CALCULATING IDEAL BODY WEIGHT IN THE EMERGENCY DEPARTMENT
}

\author{
Christine R. Stehman \\ Naval Medical Center \\ Robert G. Buckley \\ Naval Medical Center \\ Frank L. Dos Santos \\ US Naval Hospital \\ Robert H. Riffenburgh \\ San Diego State University \\ Aaron Senson \\ Dartmouth University Medical School \\ See next page for additional authors
}

Follow this and additional works at: https://digitalcommons.unl.edu/usuhs

Part of the Medicine and Health Sciences Commons

Stehman, Christine R.; Buckley, Robert G.; Dos Santos, Frank L.; Riffenburgh, Robert H.; Senson, Aaron; Mulligan, Sheila; Mjos, Nathan; and Brewer, Matt, "BEDSIDE ESTIMATION OF PATIENT HEIGHT FOR CALCULATING IDEAL BODY WEIGHT IN THE EMERGENCY DEPARTMENT" (2011). Uniformed Services University of the Health Sciences. 65.

https://digitalcommons.unl.edu/usuhs/65

This Article is brought to you for free and open access by the U.S. Department of Defense at DigitalCommons@University of Nebraska - Lincoln. It has been accepted for inclusion in Uniformed Services University of the Health Sciences by an authorized administrator of DigitalCommons@University of Nebraska Lincoln. 
Authors

Christine R. Stehman, Robert G. Buckley, Frank L. Dos Santos, Robert H. Riffenburgh, Aaron Senson, Sheila Mulligan, Nathan Mjos, and Matt Brewer 


\title{
Brief Reports
}

\section{BEDSIDE ESTIMATION OF PATIENT HEIGHT FOR CALCULATING IDEAL BODY WEIGHT IN THE EMERGENCY DEPARTMENT}

\author{
Christine R. Stehman, MD, ${ }^{*}$ Robert G. Buckley, MD, MPH, ${ }^{*}$ Frank L. Dos Santos, Do, $\dagger$ \\ Robert H. Riffenburgh, PHD, $\ddagger \S$ Aaron Swenson, MSIII,|| Sheila Mulligan, MSII, \\ Nathan Mjos, DO, ${ }^{\star *}$ and Matt Brewer, DO**

\begin{abstract}
*Naval Medical Center, San Diego, California, †US Naval Hospital, Naples, Italy, $\ddagger$ Clinical Investigations Department, Naval Medical Center, San Diego, California, §Mathematics and Statistics Department, San Diego State University, San Diego, California, \|Dartmouth University Medical School, Hanover, New Hampshire, IUniformed Services University of the Health Sciences, Bethesda, Maryland, and **Western University of Health Sciences, Pomona, California
\end{abstract} \\ Reprint Address: Robert Buckley, MD, Emergency Department, Naval Medical Center San Diego, 34800 Bob Wilson Drive,
} San Diego, CA 92134

$\square$ Abstract-Background: Ideal body weight (IBW), which can be calculated using the variables of true height and sex, is important for drug dosing and ventilator settings. True height often cannot be measured in the emergency department (ED). Objectives: Determine the most accurate method to estimate IBW using true height-based IBW that uses true height estimated by providers or patients compared to true height estimated by a regression formula using measured tibial length, and compare all to the conventional $70 \mathrm{~kg}$ male/60 kg female standard IBW. Methods: Prospective, observational, double-blind, convenience sampling of stable adult patients in a tertiary care ED from September 2004 to April 2006. Derivation set (215 patients) had blinded provider and patient true height estimates and tibial length measurements compared to gold-standard standing true height. A validation set (102 patients) then compared the accuracy of IBW using true height calculated from the regression formula vs. IBW using gold-standard true height. Regression formula for men tibial length-IBW $(\mathrm{kg})=25.83+1.11 \times$ tibial length; for women tibial length-IBW $=7.90+1.20 \times$ tibial length; $R^{2}=0.89, p<$ 0.001. Inter-rater correlation of tibial length was 0.94 . Results: Derivation set: percent within $5 \mathrm{~kg}$ of true heightbased IBW for men/women = Patient: 91.1\%:/85.7\% ; Physician: $66.1 \% / 45.1 \%$; Nurse: $65.7 \% / 47.3 \%$; tibial length: $66.1 \% / 63.7 \%$; and $70 \mathrm{~kg}$ male/60 kg female standard $46 \%$ / 75\%. Validation set: tibial length-IBW estimates were within $5 \mathrm{~kg}$ of true height-ideal body weight in only $56.2 \%$ of men and $42.2 \%$ of women. Conclusions: Patient-reported height is the best bedside method to estimate true height to calculate ideal body weight. Physician and nurse estimates of true height are substantially less accurate, as is true height obtained from a regression formula that uses measured tibial length. All methods were more accurate than using the conventional $70 \mathrm{~kg}$ male/60 $\mathrm{kg}$ female IBW standard. () 2011 Published by Elsevier Inc.

Keywords-ideal body weight; drug dosing; ventilator volume settings; medical error

\section{INTRODUCTION}

\section{Background}

Knowledge of a patient's ideal body weight (IBW) can be important for drug dosing and for calculating initial ventilator volume settings in the Emergency Department (ED). Lung capacity correlates best with lean body mass, which is a function of height, rather than actual body weight. Ventilator volume settings calculated using actual weight, particularly in obese patients, can result in excess ventilatory volumes, barotrauma, and hemody- 
namic compromise (1). Although most medications are dosed using actual, true body weight, some medications are best dosed using IBW, or a combination of IBW and actual body weight, particularly in obese patients (2-4). Although drug dosing and ventilator volume settings initiated in the ED are based on preliminary estimates and later adjusted based on the patient's response, the goal should always be to initiate drug dosing and ventilatory settings as close as possible to the patient's physiological requirements.

Multiple studies have demonstrated that ED health care providers cannot accurately or reliably predict actual body weight, and that the best bedside method to estimate a patient's actual body weight is to simply ask the patient (5-10). In a small sample of intensive care unit patients, Bloomfield et al. found that 18 of 20 bedside estimates were within $15 \%$ of true height and the majority were within $10 \%$ (11). No studies, however, have evaluated the ability of health care providers to estimate true height $(\mathrm{TH})$, and by extraction, IBW in a large ED sample of patients. Furthermore, critically ill patients often are unable to communicate their TH due to altered mental status, language barriers, or actual lack of knowledge of their precise true height. Measuring TH is often impractical in an emergent setting; it is important therefore, to know the most accurate and precise method to estimate $\mathrm{TH}$ and subsequent IBW to reduce the risk of complications associated with over- and under-ventilation and drug-dosing errors.

We performed a prospective study to determine which bedside method best predicts TH and IBW: bedside estimates by physicians or nurses, bedside anthropomorphic measurement or height as stated by the patient, or to simply use the conventional $70 \mathrm{~kg}$ male $/ 60 \mathrm{~kg}$ female IBW standard. Based on research in the fields of nutrition and forensic anthropology, we selected tibial length as the bedside anthropomorphic measurement for use in a regression model to predict TH and IBW (12). We also chose to test this method, as it seemed to be the most easily and rapidly accessible anthropomorphic measurement, short of measuring the actual height itself.

\section{METHODS}

Study Design, Setting, and Participants

This was a prospective, double-blinded, observational study. Before implementation, the local Institutional Review Board approved the study. Informed written consent was obtained for all enrollees. The study took place in an urban, tertiary care, military ED, with an annual census of approximately 62,000 visits and an Emergency
Medicine residency training program. The patient population is diverse in both age and ethnicity and includes active duty service members, dependents (children, parents, spouses, and other relatives), and retirees. Patients were enrolled on a convenience basis if they were visiting the ED on a day when an investigator was available. All medically stable patients in the ED ages 18 years or older who were able to stand for height measurement and who were able to provide oral and written consent were considered eligible for enrollment. Patients with amputations, altered mental status, inability to speak English, or with a paralysis of any kind were excluded. Enrollment in the study did not influence the patient's medical care.

\section{Methods of Measurement and Data Processing}

Tibial length (TL) was measured in centimeters with a standard measuring tape from the medial malleolus to the tibial tuberosity using a modification of the method described by Pelin and Duyar (12). The patient was asked to stand barefoot on a standard balance beam scale while his/her height was measured in centimeters. A pool of 15 attending physicians, 39 residents, and 44 nurses were selected on a convenience basis to estimate the patient's height while the patient was lying supine on a gurney. Data were collected in sequential order to ensure blinding of physicians, nurses, patients, and the investigators performing the measurements. During the derivation phase, physician, nurse, and patient estimates of TH and measurement of TL were performed, whereas only TL and $\mathrm{TH}$ were measured during the validation phase. When two investigators were available, as was the case for 49 patients, a second blinded tibial length measurement was done to evaluate inter-rater agreement.

\section{Primary Data Analysis and Outcome Measures}

IBW was calculated for each patient's gold-standard measured $\mathrm{TH}$ and for estimated $\mathrm{TH}$ using the Devine formula (13):

$$
\begin{gathered}
\text { Male IBW }(\mathrm{kg})=50+2.3 \times[(\mathrm{TH} \text { in } \mathrm{cm} / 2.54)-60] \\
\text { Female IBW }(\mathrm{kg})=45+2.3 \times[(\mathrm{TH} \text { in } \mathrm{cm} / 2.54)-60]
\end{gathered}
$$

IBW based on tibial length, TL-IBW, used simple linear regression with TL (independent) to predict TH-based IBW (TH-IBW) (dependent). The final regression models from the derivation set were then prospectively tested in a final independent group of 102 patients. We chose 5 $\mathrm{kg}$ and $10 \mathrm{~kg}$ as clinically meaningful, practical, and easily referenced cutoffs for purposes of comparing the various methods. Simple correlation was used to deter- 
Table 1. Derivation Set: By Sex for Derivation Group (124 Males, 91 Females)*

\begin{tabular}{|c|c|c|c|c|c|c|}
\hline \multirow[b]{3}{*}{ IBW Estimates from: } & \multicolumn{6}{|c|}{ Descriptors and Deviations from True Weight $(\mathrm{kg})$} \\
\hline & \multicolumn{3}{|c|}{ Males } & \multicolumn{3}{|c|}{ Females } \\
\hline & Mean (SD) & $\begin{array}{c}n(\%) \\
> \pm 5 \mathrm{~kg}\end{array}$ & $\begin{aligned} & n(\%) \\
> & \pm 10 \mathrm{~kg}\end{aligned}$ & Mean (SD) & $\begin{array}{c}n(\%) \\
> \pm 5 \mathrm{~kg}\end{array}$ & $\begin{aligned} & n(\%) \\
> & \pm 10 \mathrm{~kg}\end{aligned}$ \\
\hline True height & $70.8(7.0)$ & - & - & $51.3(7.0)$ & - & - \\
\hline Patient & $71.4(7.3)$ & $11(8.9 \%)$ & $5(4.0 \%)$ & $52.9(7.6)$ & 13 (14.3\%) & $7(7.7 \%)$ \\
\hline Physician & $72.5(6.4)$ & $42(33.9 \%)$ & $14(11.3 \%)$ & $56.8(5.5)$ & $50(54.9 \%)$ & $14(15.4 \%)$ \\
\hline Nurse & $73.4(6.0)$ & $45(36.3 \%)$ & $11(8.9 \%)$ & $55.9(5.6)$ & $48(52.7 \%)$ & $17(18.7 \%)$ \\
\hline Tibia length & $70.7(4.4)$ & $42(33.9 \%)$ & $9(7.3 \%)$ & $51.3(4.1)$ & $33(36.3 \%)$ & $6(6.6 \%)$ \\
\hline Standard $70 \mathrm{~kg}$ male or $60 \mathrm{~kg}$ female & 70 & 57 (46.0\%) & $21(16.9 \%)$ & 60 & $68(74.7 \%)$ & $41(45.1 \%)$ \\
\hline
\end{tabular}

* Mean and standard deviation, number and percent exceeding $5 \mathrm{~kg}$ and $10 \mathrm{~kg}$ absolute deviation from ideal body weight (IBW) calculated from true height.

mine inter-rater agreement between two examiners. Both Microsoft Excel (Microsoft Corporation, Redmond, WA) and Stata V10.1 (StataCorp LP, College Station, TX) were used for statistical analysis of these data.

\section{RESULTS}

A total of 330 patients were enrolled. In the derivation group, 6 patients were excluded due to lack of demographic data (no indication of gender, making an accurate IBW unable to be calculated). In the validation set, 7 patients were excluded after enrollment due to $\mathrm{TH}$ miscoding. Overall, 317 patients were enrolled and had their data evaluated for the two phases of the study.

Demographic features of both derivation and validation groups were relatively uniform: $42 \%$ female in derivation set, $45 \%$ in validation set; $56 \%$ white in the derivation set, and $63 \%$ in the validation set. The mean age was slightly higher in the derivation set: 42 years, compared to 32 years in the validation set. The inter-rater agreement for TL measurements was excellent, simple correlation coefficient of 0.94 for the 49 enrollees in the derivation set that had measurements by two investigators.

The accuracy of the various estimates of IBW (patient, nurse, physician estimates, or using a standard 70 $\mathrm{kg}$ male and $60 \mathrm{~kg}$ female) and TL-IBW obtained during the derivation phase is shown in Table 1 . Table $2 \mathrm{dem}-$ onstrates the accuracy of the TL-IBW when these two regression equations (Male Estimated $\mathrm{IBW}=25.83+$ $1.11 * \mathrm{TL}$; Female Estimated IBW $=7.90+1.20 * \mathrm{TL}$ ) derived during the derivation phase were used to calculate IBW. Figure 1 highlights the relatively wide dispersion when these two formulas were applied to the patients from the validation phase to predict IBW. Forty-four percent of males and $58 \%$ of females had IBWs greater than $5 \mathrm{~kg}$, and $10.5 \%$ of males and $26.8 \%$ of females had IBWs greater than $10 \mathrm{~kg}$ from that which was calculated using the gold-standard gender-based formula using true height (TH-IBW), Table 2.

\section{DISCUSSION}

Previous research in the ED has shown that the accuracy of simple visual bedside estimation of actual body weight is unacceptably low, and that a patient's stated weight is the most accurate method to approximate true actual body weight. We found similar results with respect to the superiority of using a patient's stated height compared to using estimated height by physicians and nurses employing simple bedside inspection or using the

Table 2. Validation Set: By Sex for Derivation Group (124 Males, 91 Females)*

\begin{tabular}{|c|c|c|c|c|c|c|}
\hline \multirow[b]{3}{*}{ IBW Estimates from: } & \multicolumn{6}{|c|}{ Descriptors and Deviations from True Weight $(\mathrm{kg})$} \\
\hline & \multicolumn{3}{|c|}{ Males } & \multicolumn{3}{|c|}{ Females } \\
\hline & Mean (SD) & $\#(\%)> \pm 5 \mathrm{~kg}$ & $\#(\%)> \pm 10 \mathrm{~kg}$ & Mean (SD) & $\#(\%)> \pm 5 \mathrm{~kg}$ & $\#(\%)> \pm 10 \mathrm{~kg}$ \\
\hline True height & 71.5 (9.3) & - & - & $54.1(10.8)$ & - & - \\
\hline Tibia length & $68.1(2.8)$ & $25(43.8 \%)$ & $6(10.5 \%)$ & $50.9(3.3)$ & $26(57.8 \%)$ & $12(26.75 \%)$ \\
\hline
\end{tabular}

* Mean and standard deviation, number and percent exceeding $5 \mathrm{~kg}$ and $10 \mathrm{~kg}$ absolute deviation from ideal body weight (IBW) calculated from true height. 


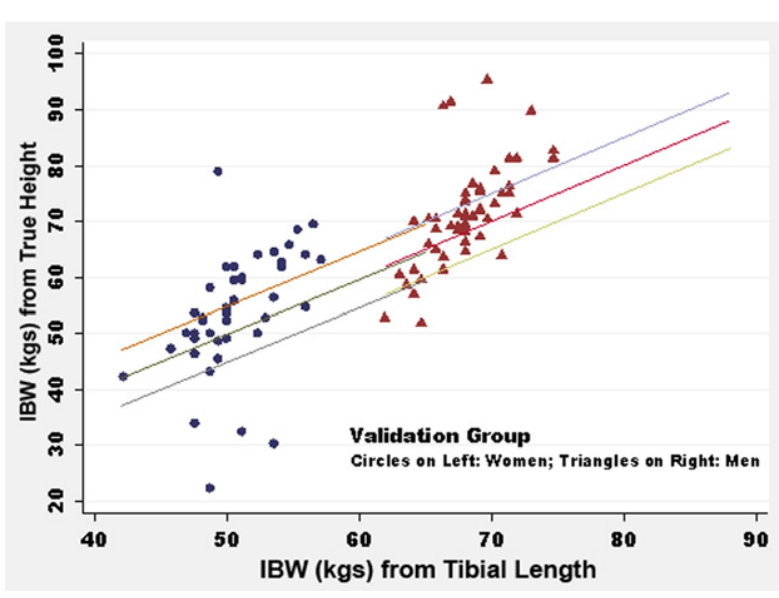

Figure 1. Regression plot from validation set of ideal body weight (IBW) calculated from true height by gender plotted against IBW calculated from the two regression formulas from the derivation phase using tibial length (TL), with $\pm 5 \mathrm{~kg}$ lines superposed. (Derivation phase regression formulas: Estimated IBW $($ men) $=25.83+1.11 \times$ TL, Estimated IBW $($ women $)=7.90+1.20 \times \mathrm{TL})$.

conventional $70 \mathrm{~kg}$ male $/ 60 \mathrm{~kg}$ female for IBW. We attempted to develop a rapidly accessible, clinically acceptable bedside method to estimate a patient's true height and subsequent IBW using the simple anthropomorphic measurement of tibial length, but found this method to be no more accurate than physician and nurse bedside estimates.

The most concerning find was that upwards of $46 \%$ of males and $75 \%$ of females, and $17 \%$ of males and $45 \%$ of females, are misclassified by over $5 \mathrm{~kg}$ and $10 \mathrm{~kg}$, respectively, when using the conventional $70 \mathrm{~kg}$ male/60 $\mathrm{kg}$ female IBW standard. In the case of ventilatory volume calculations, using Acute Respiratory Distress Syndrome Network recommendations of $6-8 \mathrm{~mL}$ per $\mathrm{kg}$ of IBW, nearly half $(45 \%)$ of our female patients would have their initial tidal volume set $80 \mathrm{~mL}$ higher or lower than their height-based IBW would have calculated. Although the risk of barotrauma or hypoventilation from this level of volume inaccuracy is relatively low, the goal of initial empirical settings is to match the patient's physiological demands.

Our data show that, as in the case with predicting actual body weight at the bedside, asking the patient to recall their height in inches is the most accurate bedside method for use in bedside IBW estimation, short of actually measuring their height. Only $4 \%$ of males and $8 \%$ of females relayed heights that would have led to a calculated IBW of $>10 \mathrm{~kg}$. Even using physician or nurse estimates of weight to calculate IBW would be preferable to using the conventional $70 \mathrm{~kg}$ male/60 kg female standard (Table 1).

\section{Limitations}

Our sample size was inadequate to stratify beyond gender for additional variables, such as ethnicity and age. We cannot rule out that when ethnicity and age are accounted for in a larger sample, TL-IBW may prove to be acceptably accurate.

Our sample population was limited to ambulatory patients who could communicate. One aim of this study was to determine whether an acceptable bedside method to estimate height and IBW could be found for critically ill ED patients who could not reliably relay their height or weight. It is unlikely that physician or nurse estimates or TL-IBW using our two regression formulas would be any more accurate when tested on such a group of patients.

\section{CONCLUSIONS}

When a patient's height is needed to calculate ideal body weight, the most rapid and accurate bedside method, short of actually measuring their true height, is to simply ask the patient to state their height in inches. Physician and nurse estimates are unacceptably inaccurate, as is the use of tibial length, in predicting true height and IBW. In all instances, using the conventional $70 \mathrm{~kg}$ male $/ 60 \mathrm{~kg}$ female IBW standard is the least accurate and should be avoided.

\section{REFERENCES}

1. Acute Respiratory Distress Syndrome Network. Ventilation with lower tidal volumes as compared with traditional tidal volumes for acute lung injury and the acute respiratory distress syndrome. N Engl J Med 2000;342:1301-8.

2. Traynor AM, Nafziger AN, Bertino JS. Aminoglycoside dosing weight correction factors for patients of various body sizes. Antimicrob Agents Chemother 1995;39:545-8.

3. Gal P, Jusko WJ, Yurchak AM, Franklin BA. Theophylline disposition in obesity. Clin Pharmacol Ther 1978;23:438-44.

4. Abernethy DR, Greenblatt DJ. Phenytoin disposition in obesity. Determination of loading dose. Arch Neurol 1985;42:468-71.

5. Anglemyer BL, Hernandez C, Brice JH, Zou B. The accuracy of visual estimation of body weight in the ED. Am J Emerg Med 2004;22:526-9.

6. Hall WL, Larkin GL, Trujillo MJ, Hinds JL, Delaney KA. Errors in weight estimation in the emergency department: comparing performance by providers and patients. J Emerg Med 2004;27:219-24.

7. Sanchez LD, Imperato J, Delapena JE, Shapiro N, Tian L. Accuracy of weight estimation by ED personnel. Am J Emerg Med 2005;23:915-6.

8. Fernandes CM, Clark S, Price A, Innes G. How accurately do we estimate patients' weight in emergency departments? Can Fam Physician 1999;45:2373-6.

9. Menon S, Kelly AM. How accurate is weight estimation in the emergency department? Emerg Med Australas 2005;17:113-6.

10. Kahn CA, Oman JA, Rudkin SE, Anderson CL, Sultani D. Can ED staff accurately estimate the weight of adult patients? Am J Emerg Med 2007;25:307-12.

11. Bloomfield R, Steel E, MacLennon G, Noble DW. Accuracy of weight and height estimation in an intensive care unit: Implications for clinical practice and research. Crit Care Med 2006;34:2153-57.

12. Pelin IC, Duyar I. Estimating stature from tibia length. A comparison of methods. J Forensic Sci 2003;48:708-12.

13. Devine BJ. Gentamicin therapy. Drug Intell Clin Pharm 1974;8:650-5. 


\section{ARTICLE SUMMARY}

\section{Why is this topic important?}

Ideal body weight (IBW), which is typically calculated from sex-based formulas using height, is important for ventilator volume settings and drug dosing.

2. What does this study attempt to show?

This study attempted to determine the best bedside method to estimate ideal body weight by determining the best method to estimate true height.

\section{What are the key findings?}

The best method to estimate height and subsequently calculate IBW is to use a patient's reported height. Physicians and nurses are unable to estimate a patient's height with reasonable accuracy, nor is a regression formula using tibial length to estimate height, nor is the use of a standard $70 \mathrm{~kg}$ male $/ 60 \mathrm{~kg}$ female, to determine IBW.

\section{How is patient care impacted?}

These findings should improve drug dosing and ventilatory settings in the Emergency Department. 